\title{
Does local cryotherapy improve thermal diagnosis similar to whole-body cryotherapy in spinal diseases?
}

\author{
Armand Cholewka $^{1} \cdot$ Agata Stanek $^{2} \cdot$ Magdalena Wójcik $^{1} \cdot$ Karolina Sieroń-Stołtny $^{3} \cdot$ \\ Zofia Drzazga ${ }^{1}$
}

Received: 4 October 2015/Accepted: 7 April 2016/Published online: 20 April 2016

(C) The Author(s) 2016. This article is published with open access at Springerlink.com

\begin{abstract}
Thermal imaging has been used for patients with spinal diseases who were qualified by their physicians for whole-body treatment or local cryotherapy. The experimental groups of patients consisted of 20 males aged $51.6 \pm 9.0$ (12 treated by whole-body cryotherapy and 8 by local cryotherapy). The distribution of the skin surface temperature was monitored by using a Thermovision Camera E60 before and immediately after body cooling. The chosen spinal region (Th5/Th6-L5/S1) was taken into consideration for all of the research groups. An essential drop in skin temperature and a better differentiation of the body surface temperatures (leading to an increase in the diagnostic value of thermography) was observed after both methods of cold impact. In order to estimate the usefulness of thermovision used after body cooling, the quantitative parameters including temperature contrast - the difference
\end{abstract}

Armand Cholewka

armand.cholewka@gmail.com

Agata Stanek

agata.stanek@gmail.com

Karolina Sieroń-Stołtny

kstoltny@hot.pl

Zofia Drzazga

zofia.drzazga@us.edu.pl

1 Department of Medical Physics, A. Chełkowski Institute of Physics, University of Silesia, Uniwersytecka 4, 40-007 Katowice, Poland

2 Department and Clinic of Internal Diseases, Angiology and Physical Medicine in Bytom, School of Medicine with the Division of Dentistry in Zabrze, Medical University of Silesia, Batorego Street 15, 41-902 Bytom, Poland

3 Chair of Physiotherapy, Department of Physical Medicine, School of Health Sciences in Katowice, Medical University of Silesia, Medyków Street 12, 40-752 Katowice, Poland between the maximum and minimum temperatures before and after cold impact and relative contrast ratio (related to the average temperature of the selected area of interest, before and after cooling, respectively)—were compared for both kinds of medical treatment. The statistical analysis proved that significant differences between the parameters obtained before and after body cooling in the case that patients treated by local and whole-body cryotherapy are similar. However, local therapy is cheaper and easy for application while whole-body therapy can give more information about the state of soft tissues for the whole back.

Keywords Thermovision diagnostics - Local cryotherapy $\cdot$ Whole-body cryotherapy $\cdot$ Physical medicine

\section{Introduction}

Internal body temperature gives us information about the condition of each part of the body. It is usually measured by contact thermometers which must be stuck to the skin for even few minutes (i.e., mercury thermometers), or put inside the organism's cavities, i.e., mouth, ear or rectum what can be problematic during children's examinations or when we are interested in studying a large body area temperature gradient [1-4].

A very simple way to avoid these problems is using noncontact thermometry thermovision. It is a well-known skin temperature gradient and its changes are also very good disease indicators and their associations with local blood flow and changing metabolism, mostly in the superficial skin layer, can bring some information about metabolism. This is why thermovision can be widely and easily used in medical diagnosis [5-16]. 
There are many different diseases in which the symptoms are manifested as an increase or decrease in internal temperature as well as skin temperature. On the other hand, there are many different physical factors used in medicine, mostly in physical medicine, that can have influence on changes in the temperature response of the human body [5-16].

This is the reason why in this work the authors tried to find out whether local body cooling, as a faster and cheaper alternative to whole-body cryotherapy, can also give additional information in thermovision diagnostics.

What are the differences between whole-body and local cryotherapy? First, whole-body cryotherapy uses a temperature lower than $-100{ }^{\circ} \mathrm{C}$ (the temperature can range from -120 to $-160{ }^{\circ} \mathrm{C}$ ) on human body, but in the case of local cryotherapy the temperature applied to the surface of the patient's body is a little higher (it depends on the distance between the cryoprobe and the body surface as well as the speed of shifting a cryoprobe over the cooled surface). Second, in whole-body cryotherapy the cryogenic temperature is applied on the patient's whole body, but in local cryotherapy it is only applied on the patient's selected part of the body. During the whole-body cryotherapy procedure, more cold receptors on the skin are stimulated, and therefore, we observed a better therapeutic effect. Third, another difference causes several favorable, physiological reactions such as: an analgesic effect, a neuromuscular effect, an antiinflammatory and anti-edematous effect, as well as a circulatory effect. However, cryogenic temperatures applied through whole body apart from the aforementioned effects also have a significant influence on the psyche, as well as the endocrine and immune systems [17, 18].

Cryotherapy is widely used, especially in the treatment of locomotor system diseases such as: the degeneration and inflammatory states of joints, osteoporosis, post-traumatic and overloading lesions and fibromyalgia [1-4, 19-22].

Both kinds of cold treatment trigger important and varied changes in the body and in the skin surface temperature gradient which causes an increase in thermal imaging's diagnostic value [7-16]. The question is if local cryotherapy's positively influential effects are comparable to whole-body ones in the case of spinal diseases.

\section{Materials and methods}

The study involved 20 non-smoking male patients (mean age $51.6 \pm 9.0$ years) with patients suffering from lower back pain who were divided by a physician into two groups: 12 patients exposed to whole-body cryotherapy procedures and 8 men exposed to local cryotherapy procedures, with no significant difference in mean age and body mass index between them.
Before the study, each patient was examined by a physician to exclude any coexisting diseases as well as any contraindications for cryotherapy procedures.

All patients included in the trial had no commonly accepted contraindications for cryotherapy as: intolerance of cold, cryoglobulinemia, Raynaud's phenomena, hypothyroidism (an increased risk of hypothermia), acute diseases of the respiratory tract, neoplastic disease (due to an adaptive intensification of local blood supply), instable angina pectoris, severe heart valve defects (in a stage of insufficient circulation), cardiac failure, severe arrhythmias, purulent-gangrenous skin lesions, vegetative neuropathies (due to predisposition to hyperhidrosis), local blood flow disturbances, cachexia and hypothermia, as well as claustrophobia and mental diseases (due to an inability to comply with the safety rules in the cryogenic chamber) $[1,2]$.

In all patients, prior to the study, a resting electrocardiogram was performed, and before each session of cryotherapy, blood pressure was measured.

The research was carried out during routine rehabilitation sessions at the following centers: the Health Resort in Goczałkowice Zdrój, the Department and Clinic of Internal Diseases, Angiology and Physical Medicine, Medical University of Silesia in Bytom. In Goczałkowice Zdrój, whole-body cryotherapy procedures were performed in a cryochamber with cold retention (Metrum Cryoflex). The temperature inside the cryochamber was $-110 \pm 10^{\circ} \mathrm{C}$. Liquid air was used to get very low temperatures in the cryogenic chamber. At the Department and Clinic of Internal Diseases, Angiology and Physical Medicine, the local cryotherapy procedures were performed. In local cryotherapy, a Froozer device was used, a nitrogen system manufactured by Technomex. The temperature at the outlet of the nozzle was $-160{ }^{\circ} \mathrm{C}$. During the WBC procedure, all patients were dressed in swimsuits, cotton socks and gloves, and wooden shoes, and their mouths and noses were protected by surgical masks and their ears by ear protectors. All jewelry, glasses and contact lenses were removed before entry into the chamber. During the WBC procedure, the subjects were walking around the chamber without touching each other. During the LC procedure, all patients were dressed only in swimsuits. The local cryotherapy procedure was applied for the Th5/Th6-L5/S1 spinal region.

All patients of both groups were exposed for 10 consecutive days to a cycle of whole-body cryotherapy or local cryotherapy procedures lasting $3 \mathrm{~min}$ a day, with a subsequent 60 -min routine of kinesiotherapy. The cryotherapy study protocol has been reviewed and approved by the Bioethical Committee of the Medical University of Silesia in Katowice (permission no. NN-6501-93/I/07), and all analyzed patients were informed about the trial and gave 
(a)

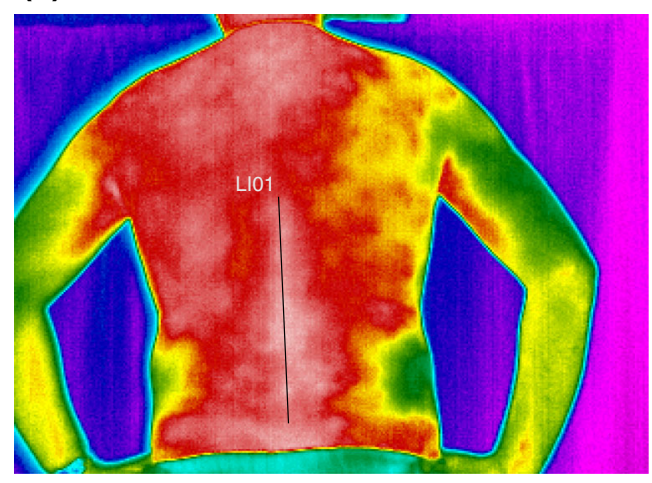

(b)

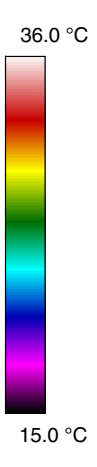

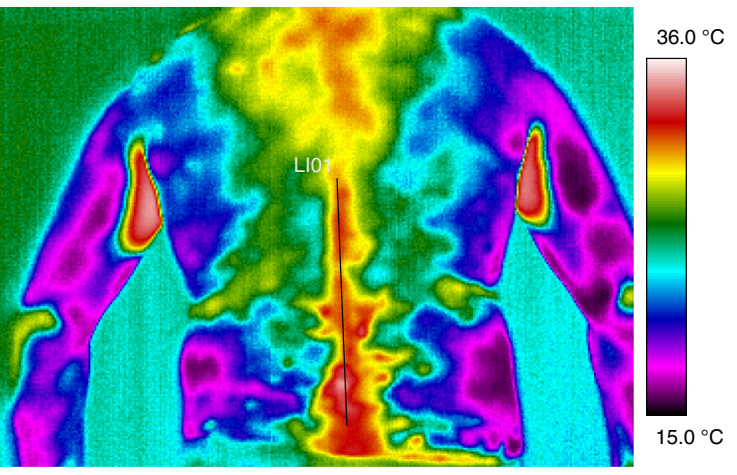

(c)

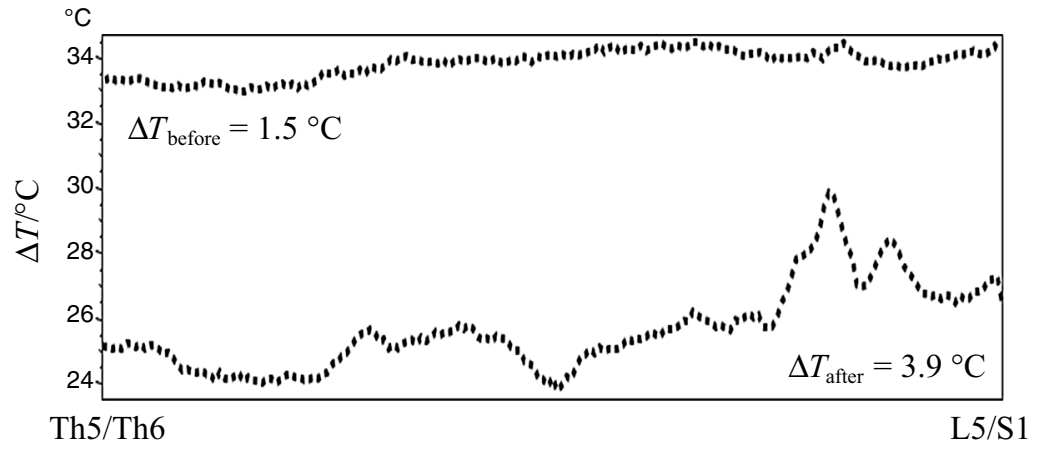

(d)

\begin{tabular}{cccccc}
\hline$\Delta T_{\text {before }}$ & $\Delta T_{\text {after }}$ & $\mathrm{TC}$ & $\mathrm{CR}_{\text {before }}$ & $\mathrm{CR}_{\text {after }}$ & $\mathrm{RCR}$ \\
\hline $1.50^{\circ} \mathrm{C}$ & $3.90^{\circ} \mathrm{C}$ & $2.60^{\circ} \mathrm{C}$ & 0.05 & 0.18 & 3.83 \\
\hline
\end{tabular}

Fig. 1 Thermal images of the back of patient four, suffering from lower back pain performed before (a) and after (b) 3 min of wholebody cryotherapy with the temperature inside the cryochamber set at $-110^{\circ} \mathrm{C}$. In addition, we included temperature plots performed before (I) and after (II) cryotherapy obtained from the line along the spinal column in the range of Th5/Th6-L5/S1 (c), as well as the calculated temperature parameters collected in the table (d)

Statistica 9.1 using t-tests, Wilcoxon's and ANOVA tests. Differences with a $p<0.05$ were regarded as significant.

\section{Results and discussion}

Thermal images of the two representative patients treated by whole-body cryotherapy (WBC-Fig. 1) and local cryotherapy (LC-Fig. 2) suffering from low back pain performed before (a) and immediately after (b) cold treatment are presented. As expected, an essential drop of skin temperature was observed due to cold impact causing a bigger differentiation of the body surface temperature and therefore an increase in the diagnostic value of thermography in contrast to what was reported in earlier papers $[2,7,11-13,15]$. The effects of the differentiation of the temperature body map inside the regions of interest (chosen lines along the spine) seen on the thermal images performed after cryotherapy seem to be similar for both 
(a)

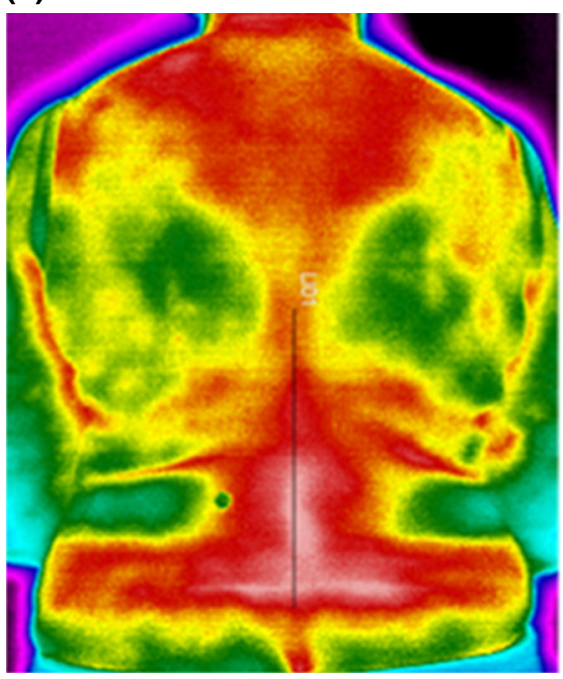

(b)

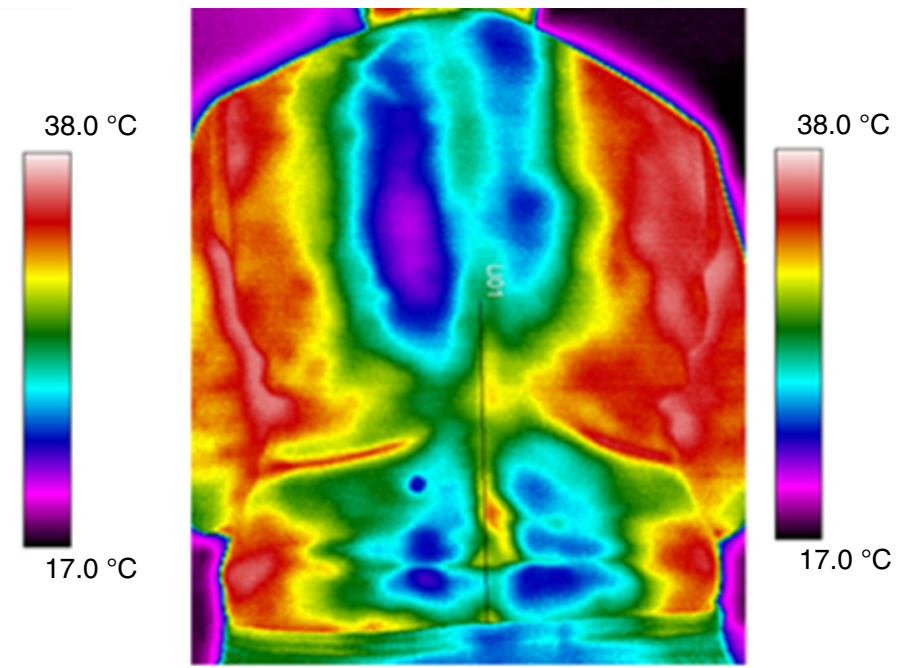

(c)

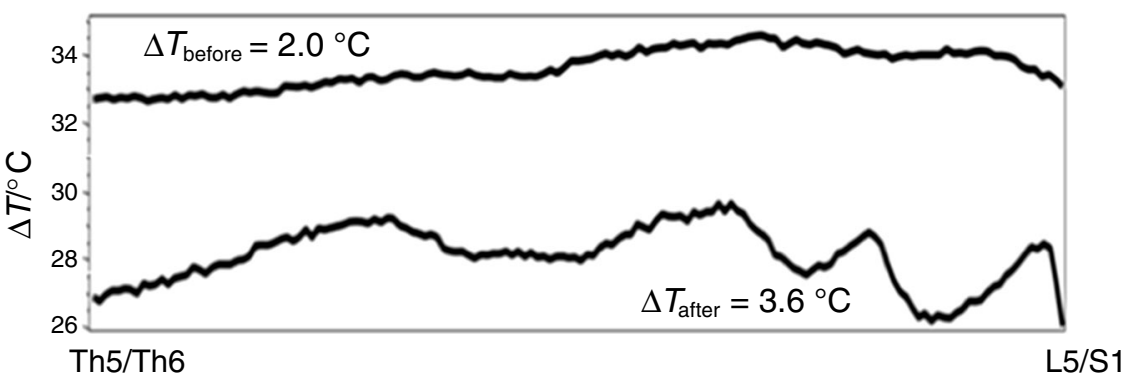

(d)

\begin{tabular}{cccccc}
\hline$\Delta T_{\text {before }}$ & $\Delta T_{\text {after }}$ & TC & $\mathrm{CR}_{\text {before }}$ & $\mathrm{CR}_{\text {after }}$ & RCR \\
\hline $2.00^{\circ} \mathrm{C}$ & $3.60^{\circ} \mathrm{C}$ & $1.80^{\circ} \mathrm{C}$ & 0.06 & 0.13 & 2.15 \\
\hline
\end{tabular}

Fig. 2 Thermal images of patient one's back suffering from lower back pain performed before (a) and after (b) 3 min of local cryotherapy. There are temperature plots performed before (I) and

therapies; however, one can see that whole-body cryotherapy cools the entire body but local cryotherapy only chosen parts of the body. In a comparison between the thermal images obtained after whole and local body cooling, it should be noted that after local cryotherapy the additional details observed on the thermal images are connected with tissues located only in the vicinity of the spinal cord because that was the area of cold air effect. On the other, when we consider the thermal image performed after whole-body cryotherapy, it is clearly seen that a decrease in temperature can be observed for all soft tissues on the entire back, not only in the vicinity of the spinal cord. Such an effect can give important additional diagnostic information not only about the spinal cord but also about a soft tissue metabolism state which is essential to determine in some back diseases. Hot spots observed in after (II) cryotherapy, obtained from the line along the spinal column in the range of Th5/Th6-L5/S1 (c), as well as the calculated temperature parameters collected in the table (d)

both thermal images presented in Fig. 1 suggest inflammatory states connected strictly with vertebrae.

However, the advantages of thermal imaging after whole-body cooling are possible to see. Some temperature changes occurred on both sides of the spinal cord may suggest the inflammatory states of soft tissues characterized, for example, in sciatica. It was also reported that the character of temperature variations depends on the degree of advancement as well as the kind of illness [2, 7, 11, 15]. These are the main differences between the qualities of effects that are visible on the thermal images.

In light of the goal of this work, to compare the influence of cold impact on temperature parameters, thermal imaging was performed in both kinds of plots along the chosen lines for all representative patients. Figures $1 \mathrm{c}$ and $2 \mathrm{c}$ show the plots of the temperature along the vertical line 
(a)

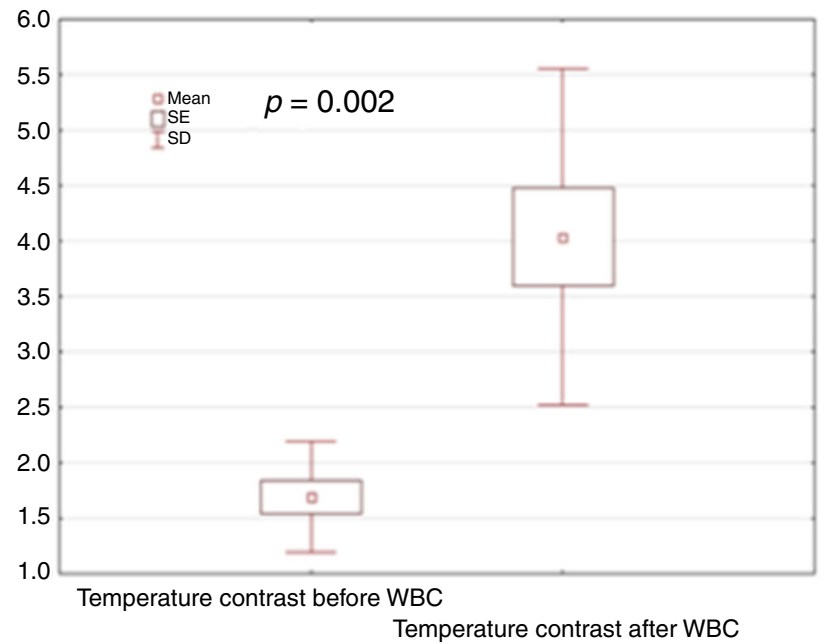

(c)

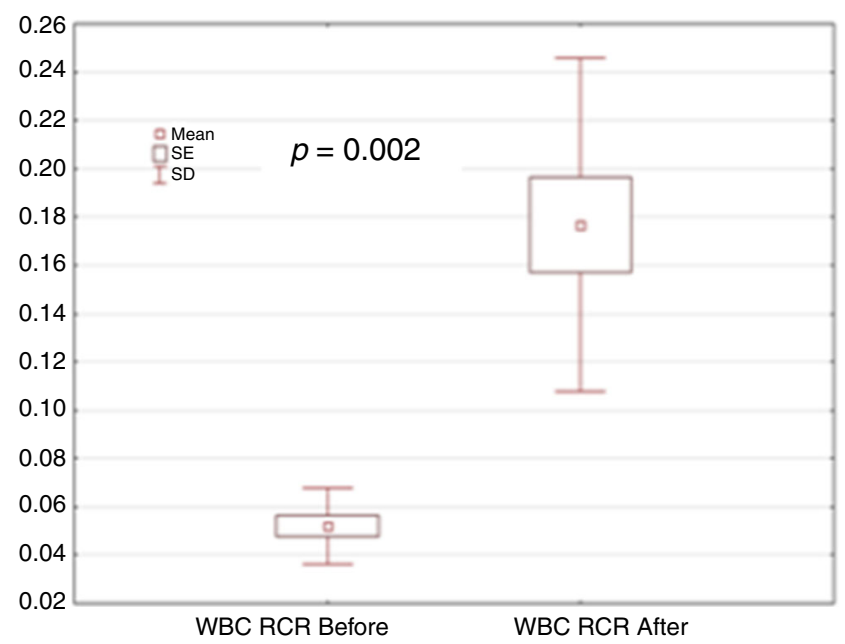

(b)

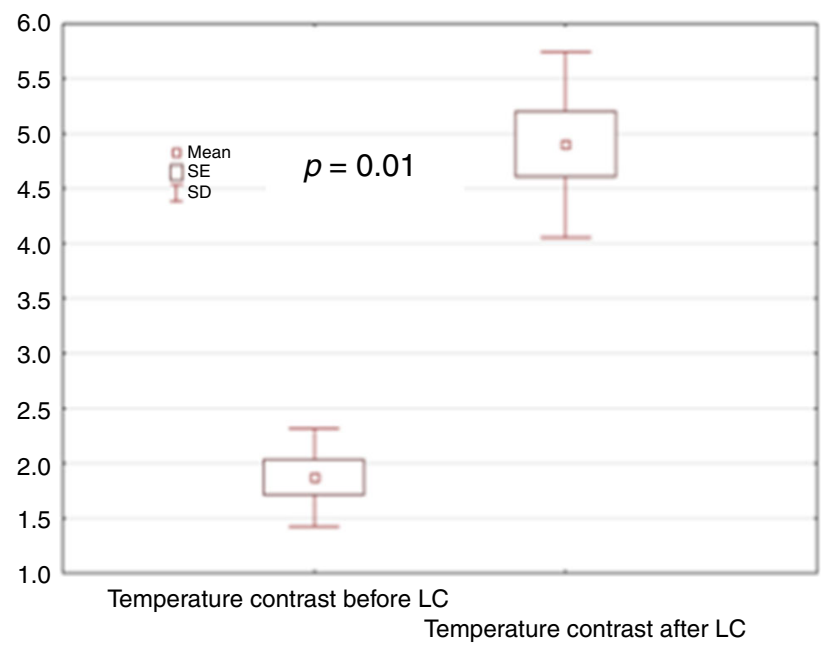

(d)

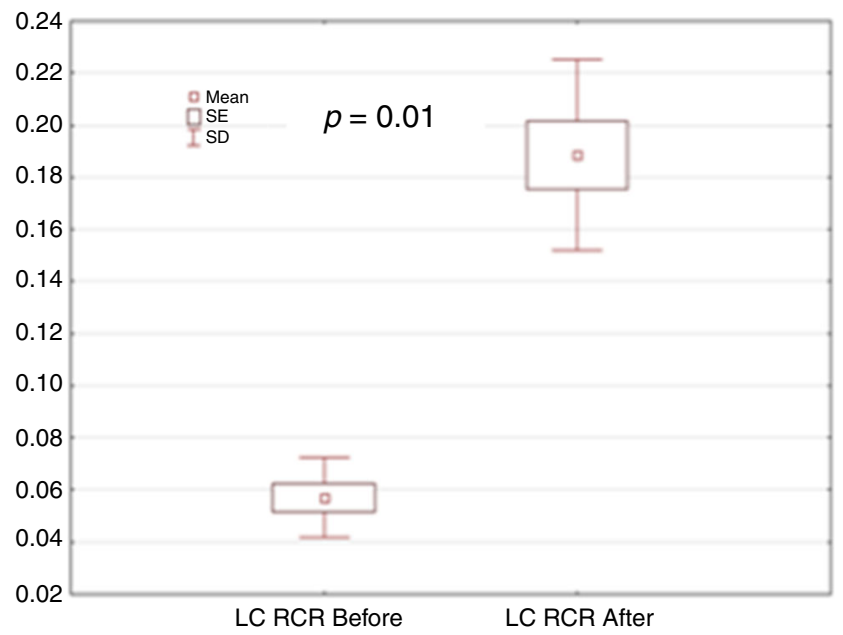

Fig. 3 These graphs show the results of a statistical analysis of the temperature contrast TC and relative contrast ratio RCR changes for patients treated by local cryotherapy (a, d) and whole-body cryotherapy $(\mathbf{b}, \mathbf{c})$

characterizing spinal vertebrae in the range of Th5/Th6L5/S1.

All statistical analysis was performed for the parameters derived from the marked range of the spinal column in the full group of patients. The marked temperature changes observed along the spine for patients after cryotherapy can be correlated with some disease processes underlying the skin, especially with spinal diseases. Hot and cold spots are visible in different ranges of the spine on thermal images which indicate inflammatory states of different vertebrae. Some quantitative parameters were needed to evaluate the usefulness of local cryotherapy in thermovision diagnostics of spinal diseases. This is the reason the lines selected along the spine in the range of vertebrates were counted; Th5/Th6-L5/S1 temperature parameters: mean $T_{\text {mean }}$, maximum $T_{\max }$, minimum $T_{\min }$. The values we discovered made it possible to calculate more specific parameters that the authors introduced in previous papers. These parameters were: difference between maximum and minimum temperature before cryotherapy $\Delta T_{\text {before }}=T_{\text {max, before }}-$ $T_{\text {min.before}}$, difference between maximum and minimum temperature after cryotherapy $\Delta T_{\text {after }}=T_{\max \text {, after }}-$ $T_{\text {min.after}}$, temperature contrast $\mathrm{TC}$ defined as difference between a maximum temperature and minimum temperature read from thermal images performed before and after cold impact $\mathrm{TC}=\Delta T_{\text {after }} / \Delta T_{\text {before }}$, contrast ratio before cryotherapy $\mathrm{CR}_{\text {before }}=\Delta T_{\text {before }} / T_{\text {mean,before }}$, contrast ratio before cryotherapy $\mathrm{CR}_{\mathrm{after}}=\Delta T_{\mathrm{after}} / T_{\text {mean,after }}$ and finally relative contrast ratio $\mathrm{RCR}=\mathrm{CR}_{\text {after }} / \mathrm{CR}_{\text {before }}$. The results of the statistical analysis of the temperature contrast TC and the relative contrast ratio RCR for all groups are shown in Fig. 3a-d. The statistical outlines proved that there are 
Table 1 Values of the temperature contrast and relative contrast ratio characterizing the spinal column in the range from Th5/Th6 to L5/S1 for patients suffering from lower back pain treated by whole-body and local cryotherapy, where: temperature contrast TC $=\Delta T_{\text {after }} / \Delta T_{\text {before }}$, and relative contrast ratio RCR is defined as $\mathrm{CR}_{\mathrm{after}} / \mathrm{CR}_{\text {before }}$

\begin{tabular}{lccclll}
\hline & $\Delta T_{\text {before }}$ & $\Delta T_{\text {after }}$ & $\mathrm{TC}$ & $\mathrm{CR}_{\text {before }}$ & $\mathrm{CR}_{\text {after }}$ & $\mathrm{RCR}$ \\
\hline \multicolumn{5}{l}{ Whole-body cryotherapy $(W B C)$} \\
P1 & 1.40 & 3.10 & 2.21 & 0.04 & 0.15 & 3.48 \\
P2 & 2.70 & 7.60 & 2.81 & 0.08 & 0.34 & 4.22 \\
P3 & 1.50 & 3.90 & 2.60 & 0.05 & 0.18 & 3.83 \\
P4 & 1.20 & 6.10 & 5.08 & 0.04 & 0.23 & 6.62 \\
P5 & 1.10 & 3.40 & 3.09 & 0.03 & 0.14 & 4.28 \\
P6 & 1.20 & 2.20 & 1.83 & 0.04 & 0.10 & 2.57 \\
P7 & 1.40 & 3.50 & 2.50 & 0.04 & 0.16 & 4.03 \\
P8 & 1.90 & 4.80 & 2.53 & 0.06 & 0.23 & 3.62 \\
P9 & 1.50 & 2.50 & 1.67 & 0.05 & 0.08 & 1.86 \\
P10 & 2.10 & 3.30 & 1.57 & 0.07 & 0.15 & 2.30 \\
P11 & 2.00 & 4.05 & 2.03 & 0.06 & 0.18 & 2.88 \\
P12 & 2.30 & 4.00 & 1.74 & 0.07 & 0.17 & 2.41 \\
Local & cryotherapy & $($ LC) & & & & \\
P1 & 2.00 & 3.60 & 1.80 & 0.06 & 0.13 & 2.15 \\
P2 & 1.40 & 4.80 & 3.43 & 0.04 & 0.18 & 4.53 \\
P3 & 1.50 & 4.20 & 2.80 & 0.04 & 0.15 & 3.38 \\
P4 & 1.40 & 6.40 & 4.57 & 0.04 & 0.25 & 5.66 \\
P5 & 2.60 & 4.50 & 1.73 & 0.08 & 0.19 & 2.19 \\
P6 & 1.70 & 5.40 & 3.18 & 0.05 & 0.21 & 3.31 \\
P7 & 2.08 & 5.32 & 2.55 & 0.06 & 0.21 & 3.31 \\
P8 & 3.30 & 5.00 & 2.17 & 0.07 & 0.19 & 2.75 \\
\hline
\end{tabular}

statistically significant differences in the temperature contrast $(p<0.05)$ as well as the relative contrast ratio $(p<0.05)$ between the parameters obtained for patients before and after body cooling in the cases of patients treated by local or whole-body cryotherapy. It means that using thermovision in combination with body cooling (whole or local cryotherapy) for patients with lower back pain diseases indicated noticeable changes on the thermal map of the body surface in the chosen body region. Such situational influences on a bigger differentiation between temperature parameters derived from the researched body areas ( $\Delta T$ is increasing) in what led to an increase in the thermal imaging diagnostic value due to cold impact $[2,7,11,15]$.

For a better interpretation of our results and an overall easier analysis, in Table 1 all of the values for the temperature contrast and relative contrast ratio TC (characterizing the spinal column) were collected in the range from Th5/Th6 to L5/S1 for patients suffering from lower back pain treated by whole-body and local cryotherapy.

However, the question is that if local body cooling is faster and cheaper than whole-body cryotherapy, can it also give additional information in thermovision diagnostics? That is why it was necessary to find out if there are significant differences between the quantitative parameters (temperature contrast TC and relative contrast ratio RCR) obtained from patients treated with whole and local cryotherapy (Fig. 4a, b).

The results of our statistics showed that there are no significant differences in the temperature contrast $(p=0.48)$ as well as relative contrast ratio $(p=0.18)$ between patients treated by local or whole-body cryotherapy. It may be pointed out that all kinds of body cooling can give additional diagnostic information on thermal images. Such knowledge may be useful because local cryotherapy is cheaper and easier to perform than whole- (a)

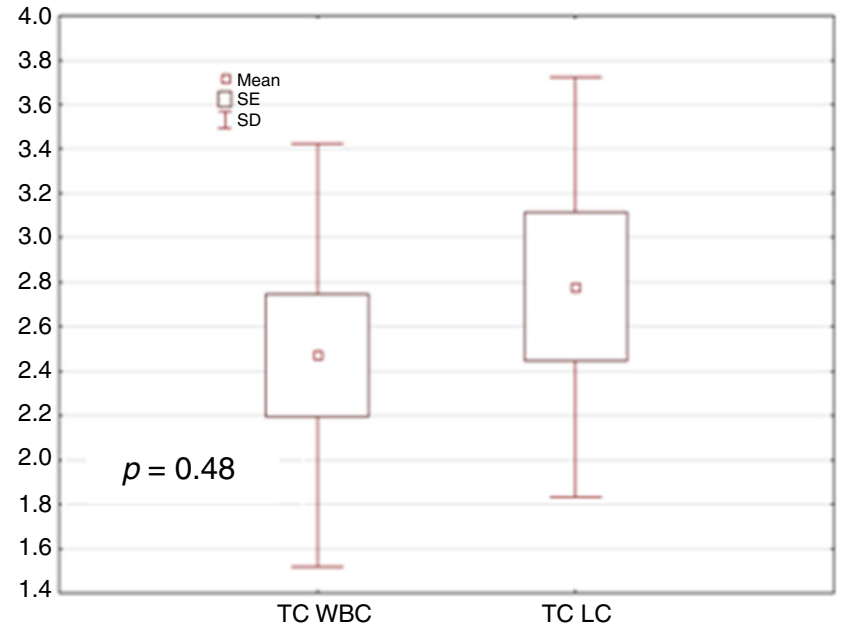

(b)

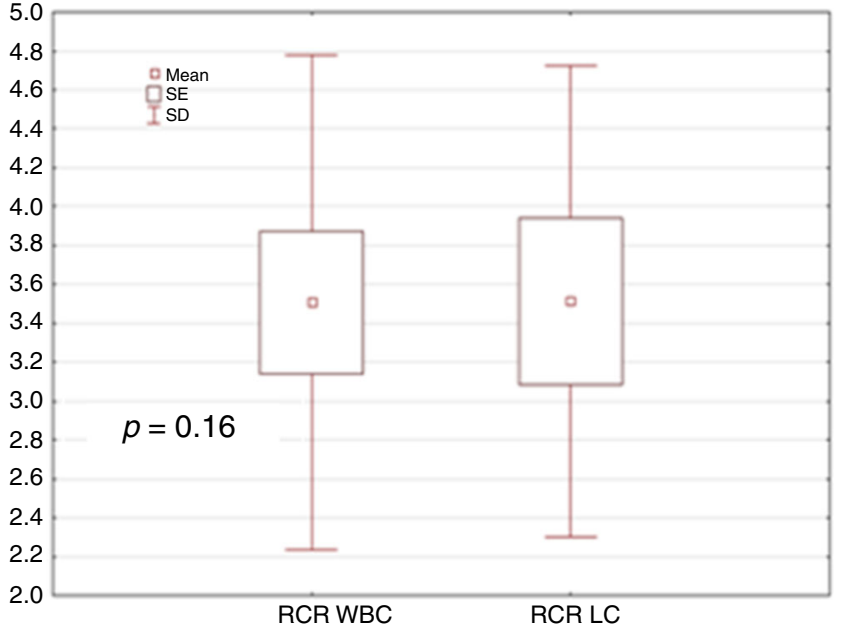

Fig. 4 These graphs show the differences between the calculated values of the temperature contrast TC (a) and relative contrast ratio RCR (b) for patients treated by local cryotherapy and whole-body cryotherapy 
Fig. 5 Plots of temperature characterizing the spinal column in the range from Th5/Th6 to L5/S1 for the two representative patients suffering from lower back pain performed after $a$ whole-body and $b$ local cryotherapy with temperature parameters

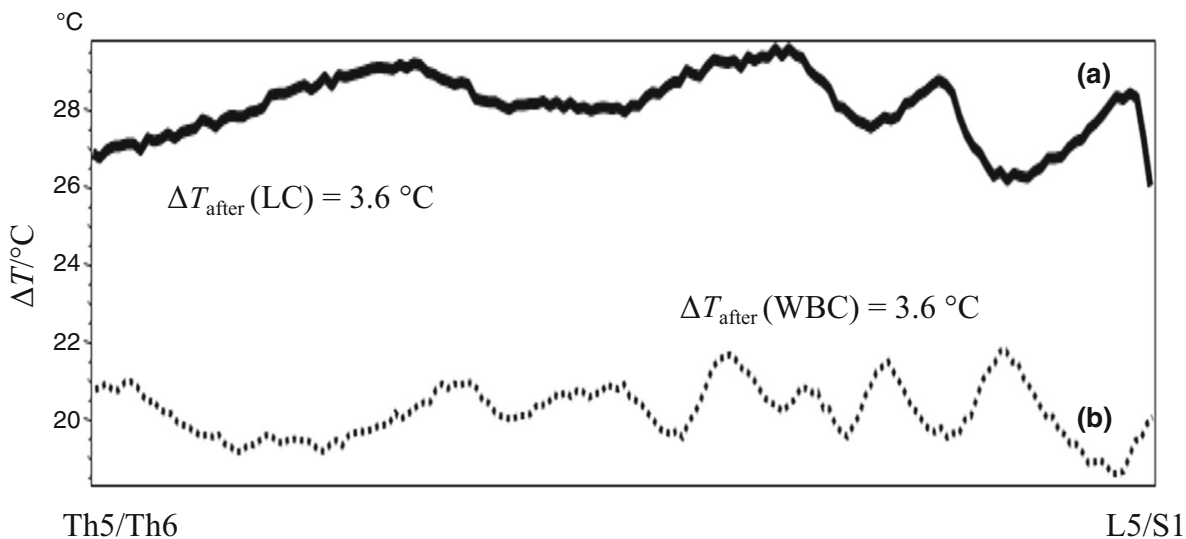

body one but can find similar diagnostic effects in some health problems such as lower back pain.

It was also interesting to see the representative temperature plots from the lines along the spine in the marked range from the patients after whole-body and local cryotherapy in Fig. 5.

The temperature plots resulting from the thermal images performed after cold impact indicated that the inflammatory states in almost the whole range for the patient treated with whole-body cryotherapy as well as for the patient treated by local cryotherapy. The temperature peaks testify about it in both cases. Moreover, the high values of temperature contrast and relative contrast ratio were evident in both of them, shown in Fig. 5.

The results of the studies point out an increase in thermal imaging diagnostic value due to cold impact-wholebody cryotherapy as well as local cryotherapy. However, it seems that thermovision diagnostics performed after whole-body cryotherapy can give more information about the metabolism state of soft tissues on the whole back unlike the local one. On the other hand, the relative contrast ratio should be more proper in the thermal characteristics of back pain in health problems and diseases as a result of using the mean temperature in our calculation which makes such a parameter more objective.

\section{Conclusions}

Thermal imaging performed after body cooling brings additional diagnostic information that can be read from thermal images.

It seems that such quantitative temperature parameters such as temperature contrast and relative contrast ratio may have potential diagnostic value also.

However, after local cryotherapy the additional details observed on curves are only connected with soft tissues located in the vicinity of the spine where the cold air affected, but when considering the thermal images performed after whole-body cryotherapy, additional diagnostic information is connected with the entire body surface and thus can be connected with metabolism and changes in states of health.

Open Access This article is distributed under the terms of the Creative Commons Attribution 4.0 International License (http://crea tivecommons.org/licenses/by/4.0/), which permits unrestricted use, distribution, and reproduction in any medium, provided you give appropriate credit to the original author(s) and the source, provide a link to the Creative Commons license, and indicate if changes were made.

\section{References}

1. Sieron A, Cieślar G. The application of cold in medicine-cryosurgery and cryotherapy. Bielsko-Biala: $\alpha$-Medica Press; 2003.

2. Podbielska H, Skrzek A. (red.) praca zbiorowa. Zastosowanie Niskich temperatur w Biomedycynie, Oficyna Wydawnicza Politechniki Wrocławskiej. 2012; 5-8, 33, 41-44, 53-54, 79-102:189-208.

3. Bauer J, Hurnik P, Zdziarski J, Mielczarek W, Podbielska H. Thermovision and its applications in medicine. Acta Bio-Opt Inf Med. 1997;3(2-4):121-31.

4. Bauer J, Hurnik P, Zdziarski J, Mielczarek W, Skrzek A, Podbielska H, Zagrobelny Z. Thermovison evaluation of cryotherapy effects. Acta Bio-Opt Inf Med. 1997;3(2-4):133-40.

5. Ammer K. Temperature effects of thermotherapy determined by infrared measurements. Phys Med. 2004;20:64-6.

6. Ring JFE. Provocation tests in thermal imaging. Thermol Int. 2001;11:2.

7. Cholewka A, Drzazga Z, Sieroń A, Stanek A. Thermovision diagnostics in chosen spine diseases treated by whole body cryotherapy. J Therm Anal Calorim. 2010;102:113-9.

8. Cholewka A, Stanek A, Kwiatek S, Sieroń A, Drzazga Z. Does the temperature gradient correlate with the photodynamic diagnosis parameter numerical colour value (NCV)? Photodiagn Photodyn Ther. 2012;10(1):33-8.

9. Cholewka A, Drzazga Z, Sieroń A, Stanek A, Knefel G, Kawecki M, Nowak M. Some applications of thermal imaging in medicine in some aspects of medical physics-in vivo and in vitro studies. Pol J Environ Stud. 2010;1:51-8.

10. Cholewka A, Knefel G, Stanek A, Kawecki M, Nowak M, Sieroń A, Drzazga Z. Thermal imaging and TC oximetry measurements of hyperbaric oxygen therapy (HBO) effects on trophic ulceration of the crura. J Therm Anal Calorim. 2012;108(1):25-31. 
11. Cholewka A, Drzazga Z, Michnik A, Sieroń A, Wiśniowska B. Temperature effects of whole cryotherapy determined by termography. Thermol Int. 2004;14:57-63.

12. Boerner E, Bauer J, Ratajczyk B, Dereń E, Podbielska H. Application of thermovision for analysis of superficial temperature distribution changes after physiotherapy. J Therm Anal Calorim. 2015;120(1):261-7.

13. Boerner E, Bauer J, Kuczkowska M, Podbielska H, Ratajczyk B. Comparison of the skin surface temperature on the front of thigh after application of combined red-IR radiation and diadynamic currents executed in different sequence. $\mathbf{J}$ Therm Anal Calorim. 2015;120(1):921-8.

14. Mercer V, Ring EFJ. Fever screening and infrared thermal imaging: concerns and guideliner. Thermol Int. 2009;19(3):67-9.

15. Cholewka A, Drzazga Z, Sieron A. Monitoring of whole body cryotherapy effects by thermal imaging-preliminary report. Phys Med. 2006;22(2):57-62.

16. Banfi G, Lombardi G, Colombini A, Melegati G. Whole-body cryotherapy in athletes. Sports Med. 2010;40(6):509-17.

17. Stanek A, Cieślar G, Strzelczyk K, Kasperczyk S, Wiczkowski A, Birkner E, Sieroń A. Influence of cryogenic temperatures on inflammatory markers in patients with ankylosing spodylitis and healthy volunteers. J Environ Stud. 2010;19(1):67-175.

18. Stanek A, Cholewka A, Gaduła J, Drzazga Z, Sieroń A, SierońStołtny K. Can whole-body cryotherapy with subsequent kinesiotherapy procedures in closed type cryogenic chamber improve BASDAI, BASFI, some spine mobility parameters and decrease pain intensity in patients with ankylosing spondylitis? BioMed Res Int. 2015;2015:1-12.
19. Kerschan-Schindl K, Uher EM, Zauner-Dungl A, Fialka-Moser V. Cold and cryotherapy. A review of the literature on general principles and practical applications. Acta Med Austriaca. 1998;25(3): 73-8.

20. Metzger D, Zwingmann C, Protz W, Jackel WH. Die Bedeutung der Ganzkorperkaltetherapie im Rahmen der Rehabilitation bei Patienten mit rheumatishen Erkrank. Rehabil. 2000;39:93-100.

21. Korman P, Straburzyńska-Lupa A, Romanowski W, Trafarski A. Temperature changes in rheumatoid hand treated with nitrogen vapors and cold air. Rheumatol Int. 2012;32(10):2987-92.

22. Wilk M, Trąbka R, Śliwiński Z. Changes in knee joint thermograms following local cryotherapy combined with various physiotherapy regiments. Fizjoterapia Polska. 2008;8(3):267-71.

23. Ammer K. The Glamorgan protocol for recording and evaluation of thermal images of the human body. Thermol Int. 2008;18(4): $125-9$.

24. Ring EFJ, Ammer K. The technique of infrared imaging in medicine. Thermol Int. 2000;10(1):7-14.

25. Dębiec-Bạk A, Skrzek A, Podbielska H. Application of thermovision for estimation of the optimal and safe parameters of the whole body cryotherapy. J Therm Anal Calorim. 2003;111(3): 1853-9. 